BMC

Genomics

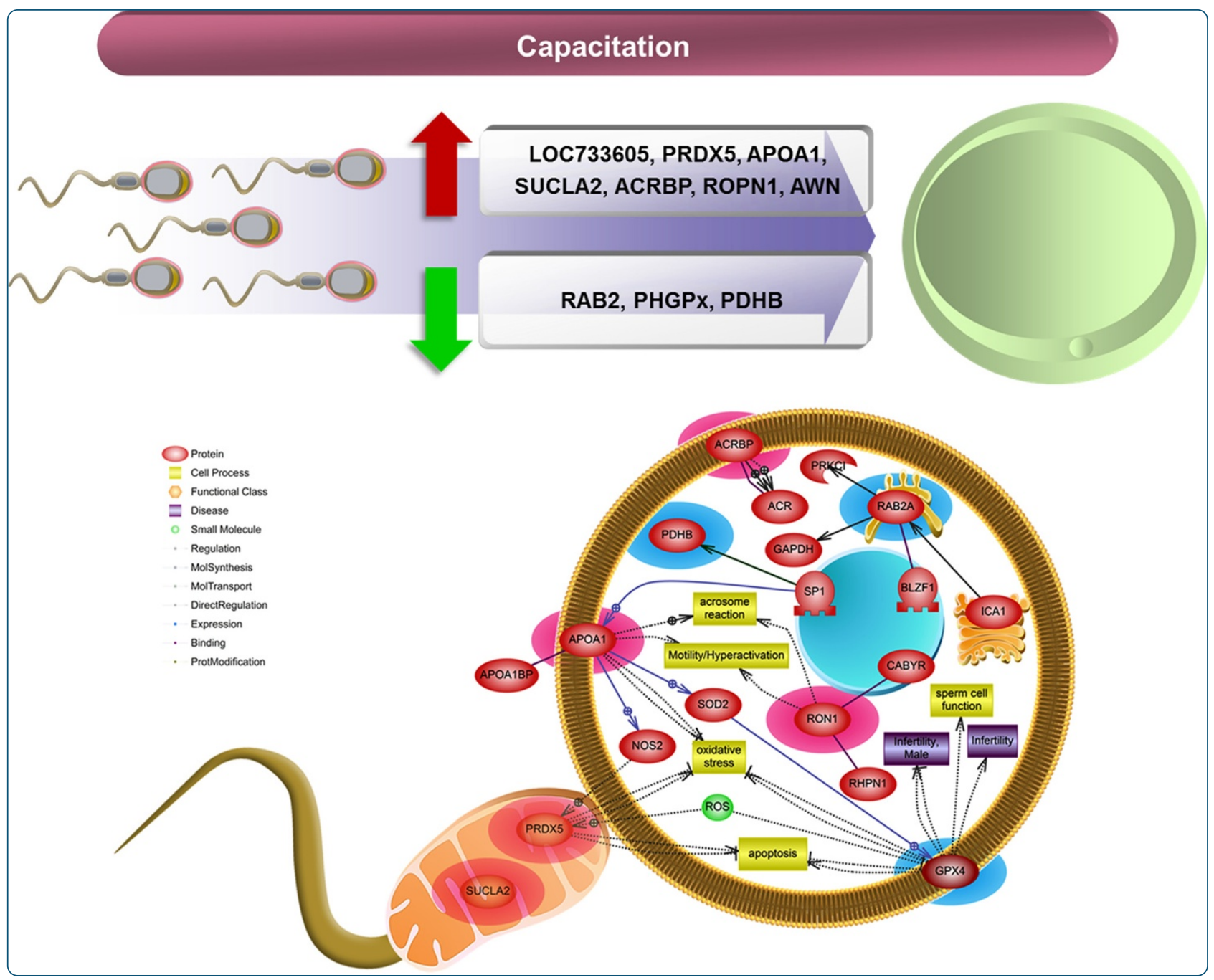

\title{
A comprehensive proteomic approach to identifying capacitation related proteins in boar spermatozoa
}

Kwon et al. 


\title{
A comprehensive proteomic approach to identifying capacitation related proteins in boar spermatozoa
}

\author{
Woo-Sung Kwon', Md Saidur Rahman', June-Sub Lee', Jin Kim', Sung-Jae Yoon', Yoo-Jin Park', Young-Ah You', \\ Seongsoo Hwang ${ }^{2}$ and Myung-Geol Pang ${ }^{1^{*}}$
}

\begin{abstract}
Background: Mammalian spermatozoa must undergo capacitation, before becoming competent for fertilization. Despite its importance, the fundamental molecular mechanisms of capacitation are poorly understood. Therefore, in this study, we applied a proteomic approach for identifying capacitation-related proteins in boar spermatozoa in order to elucidate the events more precisely. 2-DE gels were generated from spermatozoa samples in before- and after-capacitation. To validate the 2-DE results, Western blotting and immunocytochemistry were performed with 2 commercially available antibodies. Additionally, the protein-related signaling pathways among identified proteins were detected using Pathway Studio 9.0.

Result: We identified Ras-related protein Rab-2, Phospholipid hydroperoxide glutathione peroxidase (PHGPX) and Mitochondrial pyruvate dehydrogenase E1 component subunit beta (PDHB) that were enriched before-capacitation, and NADH dehydrogenase 1 beta subcomplex 6, Mitochondrial peroxiredoxin-5, (PRDX5), Apolipoprotein A-I (APOA1), Mitochondrial Succinyl-CoA ligase [ADP-forming] subunit beta (SUCLA2), Acrosin-binding protein, Ropporin-1A, and Spermadhesin AWN that were enriched after-capacitation (>3-fold) by 2-DE and ESI-MS/MS. SUCLA2 and PDHB are involved in the tricarboxylic acid cycle, whereas PHGPX and PRDX5 are involved in glutathione metabolism. SUCLA2, APOA1 and PDHB mediate adipocytokine signaling and insulin action. The differentially expressed proteins following capacitation are putatively related to sperm functions, such as ROS and energy metabolism, motility, hyperactivation, the acrosome reaction, and sperm-egg interaction.
\end{abstract}

Conclusion: The results from this study elucidate the proteins involved in capacitation, which may aid in the design of biomarkers that can be used to predict boar sperm quality.

Keywords: Capacitation, Proteomics, Boar, Spermatozoa, 2DE

\section{Background}

Ejaculated spermatozoa undergo marked structural and biochemical changes within the female reproductive tract before fertilization. Although spermatozoa are motile and morphologically normal after ejaculation, they are unable to fertilize an oocyte. Subsequently, spermatozoa are exposed to a new environment where numerous chemicals in the female genital track trigger a cascade of metabolic and structural alterations associated with

\footnotetext{
* Correspondence: mgpang@cau.ac.kr

'Department of Animal Science \& Technology, Chung-Ang University,

Anseong, Gyeonggi-do 456-756, Republic of Korea

Full list of author information is available at the end of the article
}

changes in membrane fluidity, intracellular bicarbonate and calcium levels, cAMP, PKA activity, and tyrosine phosphorylation of proteins [1-10]. This time-dependent acquisition of fertilizing competence has been termed "capacitation" [11,12]. Proteomic studies have been conducted to elucidate the molecular mechanisms underlying capacitation for humans [13], mice [14], hamsters [15], boars [16], and bulls [17]. In most cases, these studies identified specific set of proteins and tyrosine-phosphorylated proteins that are involved in capacitation [13-17]. Mature spermatozoa are unable of transcription, translation, and protein synthesis [18]. However, a new viewpoint has been presented that ejaculated spermatozoa are capable 
of utilizing mRNA transcripts for protein translation during their functional maturation [19]. Simultaneously, it is well accepted that spermatozoa acquire their functionality via post-translational protein modifications such as phosphorylation $[20,21]$. It has been demonstrated that freezethawing of human spermatozoa results in differential expression of twenty-seven proteins compare to their fresh ejaculate [20]. This study suggested that cryopreservation may be induced spermatozoa dysfunction due to protein degradation and protein phosphorylation [20,21]. Therefore, it is a matter of paramount importance to detect a set of differentially expressed proteins associated with capacitation as well as other functional state of spermatozoa.

Successful fertilization requires that spermatozoa complete to capacitate at right time both in vitro and in vivo. Therefore, measuring the fraction of a sperm population that is able to capacitated will possibly be an excellent criteria to measure semen quality. Literature demonstrated that the prediction of male fertility of mammals still depends on conventional sperm analysis, such as sperm morphology [22-24], motility [25-27], and sperm penetration assays $[28,29]$, and their clinical value has been disputed [30]. Therefore, the accurate and broadly applicable methods for semen assessment might help to analyze male fertility.

Recent advances through performing two-dimensional electrophoresis (2-DE) for the separation of proteins and mass spectrometry (MS) for peptide sequencing have facilitated protein identification, leading to the rapid expansion of sperm proteomic research. A previous study in our laboratory established a suitable in vitro assay of male fertility for performing fertility-related proteomics of bull spermatozoa [31]. Therefore, the present study employed proteomic outlining of boar spermatozoa following capacitation in order to elucidate this extremely important event. A comprehensive and comparative proteomic study was carried out to explore the changes in protein expression ( $>3$-fold) during capacitation. Sperm motility (\%), motion kinematics, capacitation status, and tyrosine phosphorylation were analyzed using combined computer-assisted sperm analysis (CASA), Hoechst 33258/ chlortetracycline fluorescence assessment (H33258/CTC), and Western blotting, respectively. Next, the 2-DE results were confirmed using Western blotting and immunocytochemistry. Finally, related signaling pathways were constructed based on the differentially expressed proteins.

\section{Results}

Sperm motility, motion kinematics, capacitation status, and tyrosine phosphorylation

To measure the motility parameters of before- and aftercapacitation spermatozoa, we performed CASA technique as described in the Methods. A variety of motion parameters, including hyperactivated motility (HYP), curvilinear velocity (VCL), and mean amplitude of head lateral displacement $(\mathrm{ALH})$ were significantly increased in after-capacitation compare to before-capacitation spermatozoa $(P<0.05$, Table 1$)$. However, straight-line velocity (VSL) was significantly decreased in after-capacitation $(P<0.05$, Table 1$)$. In present study, the dual staining method was performed to evaluate the changes in capacitation status both before- and after-capacitation spermatozoa. The acrosome reacted (AR) and capacitated (B) patterns were significantly increased in after-capacitation $(P<0.05)$, while the non-capacitated $(\mathrm{F})$ pattern was significantly decreased in after-capacitation spermatozoa $(P<0.05)$. It has been demonstrated that capacitation of mammalian spermatozoa are associated to the activation of a cAMP/PKA-dependent signaling pathways followed by up-regulation of protein tyrosine phosphorylation $[8,9]$. Therefore, next we measured the levels of tyrosine phosphorylation in both groups of spermatozoa. Four different tyrosine phosphorylated protein bands (approximately 18, 26, 34, and $36 \mathrm{kDa}$ ) were significantly increased in after-capacitation $(P<0.05$, Figure 1$)$ compare to before-capacitation spermatozoa.

\section{Proteomic analysis and identification of capacitation proteins}

A total of 224 protein spots were detected, and 10 spots showed significantly different expression ( $>3$-fold difference; $P<0.05)$ between the before- and after-capacitation spermatozoa (Figure 2). Among them, 3 spots were enriched in the before-capacitation group, while 7 spots were enriched in the after-capacitation group (Figure 3). The differentially expressed spots ( $>3$-fold) were identified by an MS/MS ion search using MASCOT software (Matrix Science). Notably, the 3 spots in the beforecapacitation group included the Ras-related protein Rab-2 (RAB2), Phospholipid hydroperoxide glutathione peroxidase (PHGPx), and pyruvate dehydrogenase E1 component

\begin{tabular}{|c|c|c|}
\hline $\begin{array}{l}\text { Sperm motility and } \\
\text { motion kinematics }\end{array}$ & Before-capacitation & After-capacitation \\
\hline MOT (\%) & $85.33 \pm 2.80$ & $87.42 \pm 1.77$ \\
\hline HYP (\%) & $5.76 \pm 1.42$ & $15.89 \pm 2.26^{*}$ \\
\hline VCL $(\mu \mathrm{m} / \mathrm{s})$ & $119.56 \pm 2.22$ & $147.28 \pm 5.04^{*}$ \\
\hline VSL $(\mu \mathrm{m} / \mathrm{s})$ & $75.87 \pm 0.97$ & $64.85 \pm 1.00^{*}$ \\
\hline $\operatorname{VAP}(\mu \mathrm{m} / \mathrm{s})$ & $81.06 \pm 2.48$ & $81.57 \pm 2.51$ \\
\hline $\mathrm{ALH}(\mu \mathrm{m})$ & $5.9 \pm 0.19$ & $6.97 \pm 0.24^{*}$ \\
\hline
\end{tabular}

Sperm motility and motion kinematics are presented as mean $\pm S E M, n=3$, ${ }^{*} P<0.05$. MOT = motility (\%); HYP = hyperactivated sperm (\%); $\mathrm{VCL}=$ curvilinear velocity $(\mu \mathrm{m} / \mathrm{s}) ; \mathrm{VSL}=$ straight-line velocity $(\mu \mathrm{m} / \mathrm{s}) ; \mathrm{VAP}=$ average path velocity $(\mu \mathrm{m} / \mathrm{s}) ; \mathrm{ALH}=$ mean amplitude of head lateral displacement $(\mu \mathrm{m})$. 


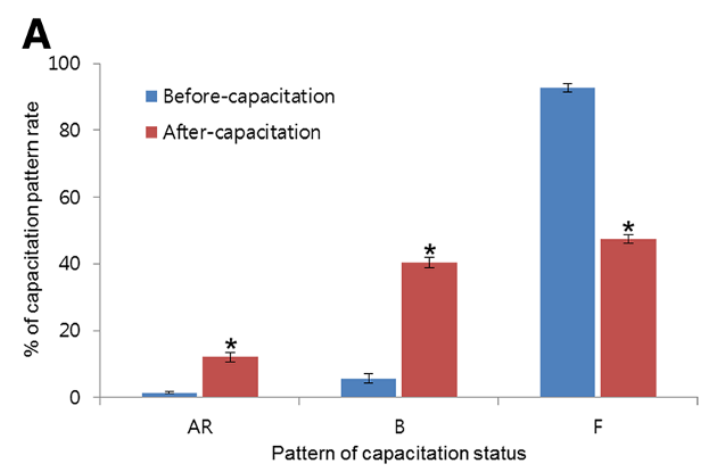

\section{B}

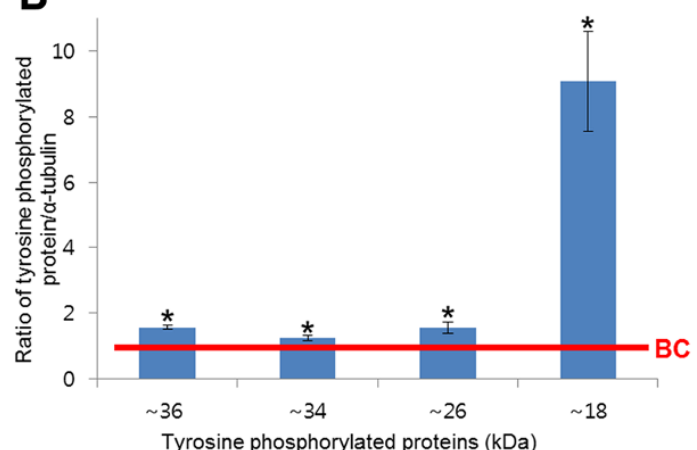

Tyrosine phosphorylated proteins $(\mathrm{kDa})$

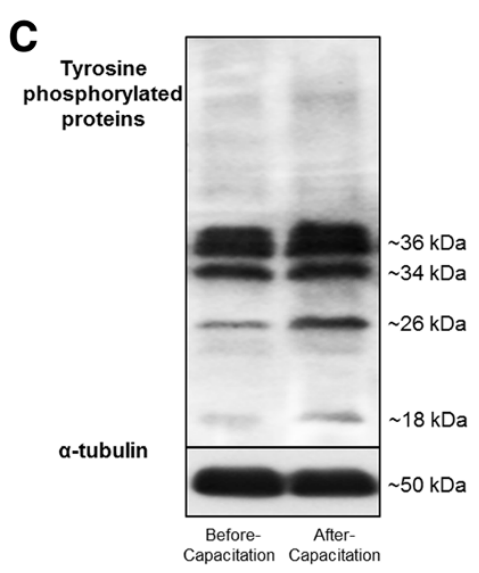

Figure 1 Capacitation status and tyrosine phosphorylation of spermatozoa following incubation in capacitation media. (A) Changes in capacitation pattern. Data represent mean $\pm \mathrm{SEM}, \mathrm{n}=3,{ }^{*} P<0.05$. (B) Ratios of tyrosine phosphorylated proteins (optical density [OD] $\times \mathrm{mm}$ )/a-tubulin $(\mathrm{OD} \times \mathrm{mm})$. Data represent mean $\pm \mathrm{SEM}, \mathrm{n}=3, * P<0.05$. The red line indicates the landmark of before-capacitation (BC). (C) Tyrosine-phosphorylated proteins were probed with anti-Phosphotyrosine (4G10) antibody; lane 1: before capacitation; lane 2: after capacitation.

subunit beta, mitochondrial (PDHB). On the other hand, the 7 highly expressed spots in the after-capacitation group were NADH dehydrogenase 1 beta subcomplex 6 (LOC733605), Peroxiredoxin-5, mitochondrial (PRDX5), Apolipoprotein A-I (APOA1), Succinyl-CoA ligase [ADPforming] subunit beta, mitochondrial (SUCLA2), Acrosinbinding protein (ACRBP), ropporin-1A (ROPN1), and spermadhesin AWN (AWN) (Table 2).

\section{Protein confirmation by western blotting and immunofluorescence}

To validate the 2-DE results, the differentially expressed proteins were further examined by Western blotting analysis by using commercially available antibodies. In after-capacitation spermatozoa, PRDX5 and PHGPx were detected at $\sim 20$ and $22 \mathrm{kDa}$, respectively. The density of PRDX5 increased $(P<0.05)$, while the density of PHGPx was decreased $(P<0.05)$ following capacitation. Additionally, these proteins were detected by immunofluorescence using the corresponding antibodies along with lectin PNA (to detect the acrosomal region) and DAPI (to detect the nucleus) in spermatozoa following capacitation. PRDX5 was detected in the midpiece, and PHGPx was detected in the acrosome and midpiece. These protein expression patterns were similar to the expression patterns detected by Western blotting (Figure 4).

\section{Signaling pathway}

The gene name of each differentially expressed protein was confirmed by performing a database search, and the results were imported into Pathway Studio to identify their signaling pathways. Three pathways were significantly correlated with 5 of the proteins (Table $3, P<0.05$ ). SUCLA2 and PDHB were significantly correlated with the tricarboxylic acid cycle, whereas PHGPx and PRDX5 were significantly correlated with glutathione metabolism (Table 3, $P<0.05)$. SUCLA2, APOA1, and PDHB were correlated with adipocytokine signaling and insulin action (Table $3, P<0.05$ ). Figure 5 illustrates the cellular pathways regulated by the differentially expressed proteins in spermatozoa [18]. At least 8 proteins were implicated in different sperm-specific process. These proteins were putatively related to sperm functions, such as ROS and energy metabolism, motility, hyperactivation, the acrosome reaction, and male fertility.

\section{Discussion}

Proteomic techniques have enabled the investigation of sperm-specific cellular processes. Such studies have been pivotal in identifying and designing valid biomarkers of male fertility [31,32]. Spermatozoa must undergo capacitation before fertilizing an oocyte $[9,10]$, and the process is associated with changes in protein content. It is generally 


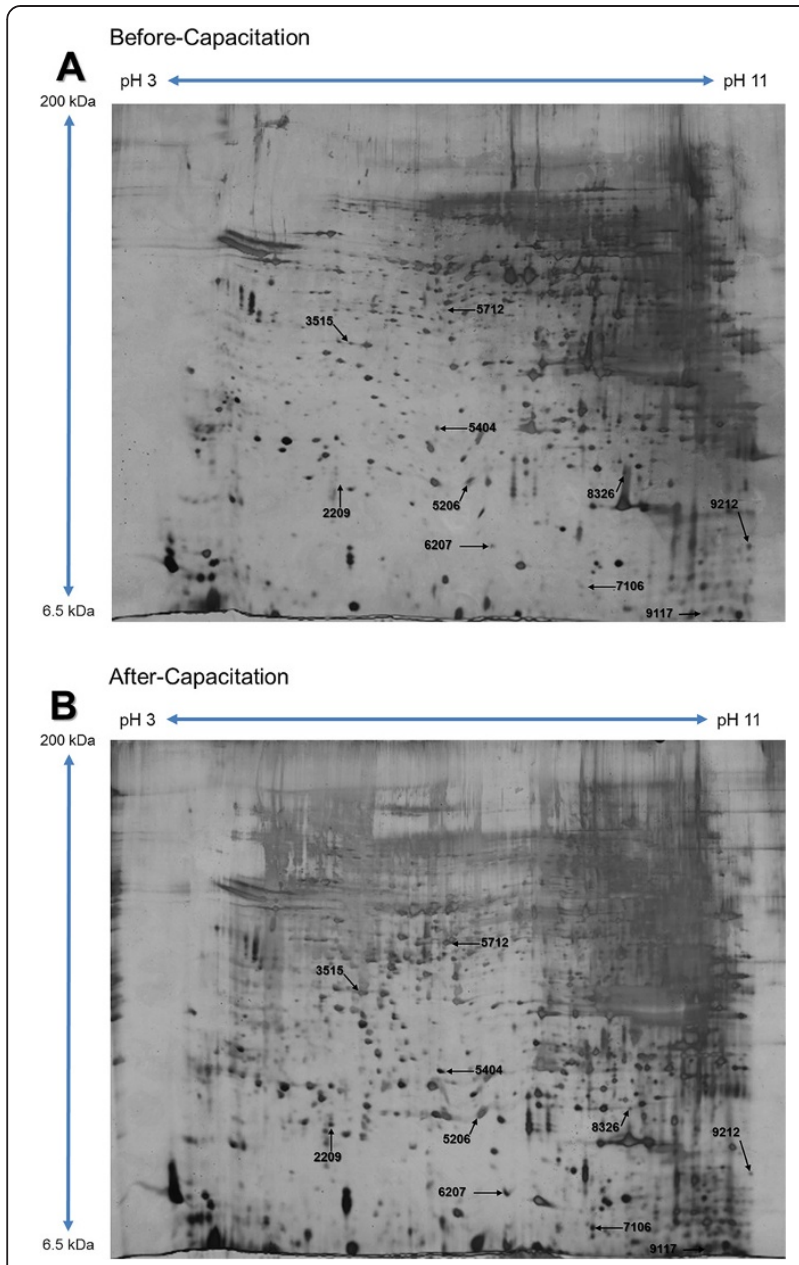

Figure 2 Separation of proteins by 2-DE. 2-DE gels were stained with silver nitrate and analyzed using PDQuest 8.0 software. (A) Protein spots from before-capacitation spermatozoa. (B) Protein spots from after-capacitation spermatozoa. believed that spermatozoa are unable to transcription, translation, and protein synthesis [33,34]. However, reports also exist spermatozoa are capable of synthesis new proteins [35]. Therefore, proteomic profiling of boar spermatozoa following capacitation may elucidate the proteins involved in capacitation.

Capacitation is an important pre-requisite to fertilization. During this process, tyrosine phosphorylation occurs in spermatozoa, which triggers a change in motion kinematics and morphology [1-5]. In the present study, capacitation was induced by heparin and was confirmed by measuring changes in tyrosine phosphorylation, sperm motility, motion kinematics, and CTC patterns. As a result of capacitation, there was a significant increase in tyrosine-phosphorylated proteins, HYP, VCL, ALH, and capacitation status $(P<0.05$, Table 1 and Figure 1). In addition, VSL was a significantly decreased in after-capacitation $(P<0.05$, Table 1$)$. These results indicate
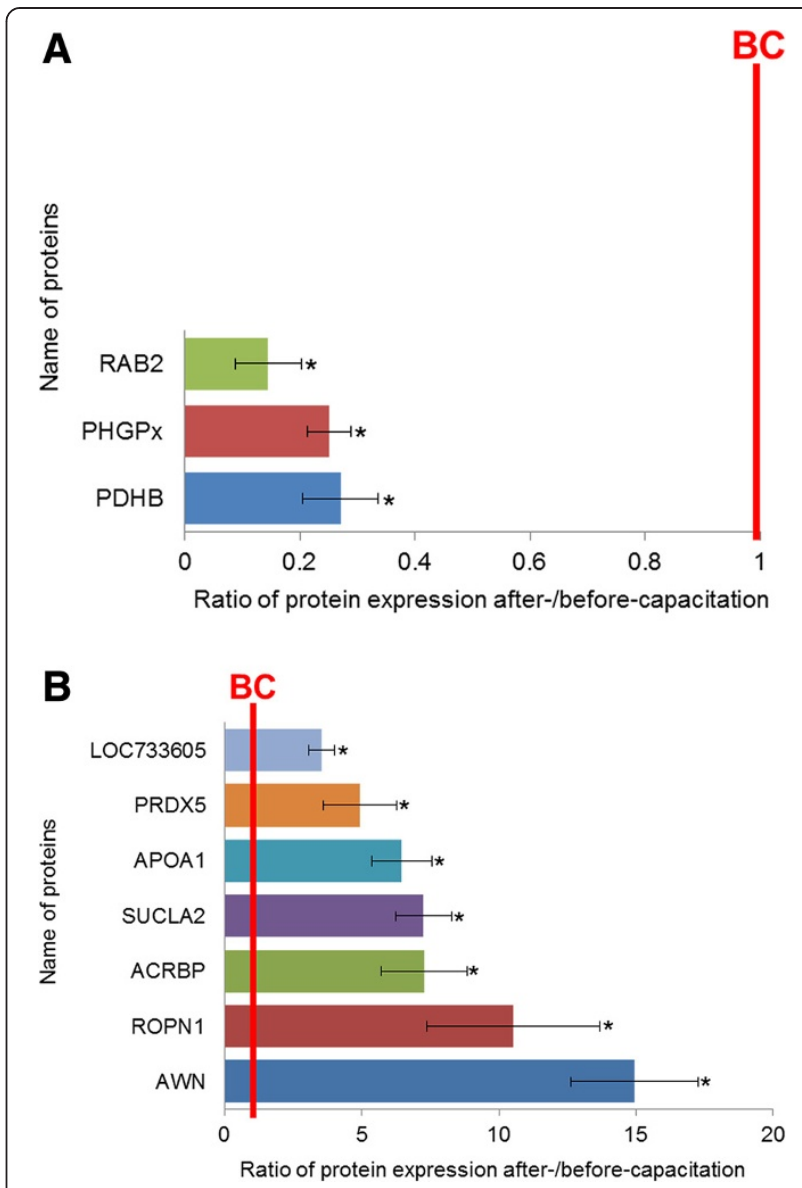

Figure 3 Comparison of proteins from before- and aftercapacitation spermatozoa. Differentially expressed ( $>3$-fold) proteins were determined by comparing before- and aftercapacitation spermatozoa ( $\left.{ }^{*} P<0.05\right)$. The line indicates the landmark of before-capacitation (BC). (A) Three proteins were significantly decreased after capacitation. (B) Seven proteins were significantly increased after capacitation. The data represent the mean \pm SEM, $n=3$.

that we achieved optimum capacitation in vitro in boar spermatozoa.

To identify marked changes in protein expression $(>3-$ fold), spermatozoa were separated by Percoll and analyzed by 2-DE in before- and after-capacitation (Table 2 and Figure 2). Three proteins were abundant in beforecapacitation, and 7 were abundant in after-capacitation (Figure 3). Finally, we used Pathway Studio to search for the identified proteins and construct signaling pathways involved in the capacitation process. To validate the 2DE results, Western blotting and immunofluorescence were performed with commercially available antibodies to detect the differentially expressed proteins.

RAB2, PHGPx, and PDHB were decreased after capacitation (Figure $3 \mathrm{~A}$ ). RAB2A and RAB2B are 2 subgroups of RAB2 proteins [36]. Members of the RAB family of proteins play a critical role in regulating vesicular transport 
Table 2 Differentially expressed (>3-fold) proteins identified by ESI-MS/MS

\begin{tabular}{|c|c|c|c|c|c|}
\hline Spot no. & gi no. & Symbol & Protein description & Peptide sequence & $\begin{array}{l}\text { Mascot } \\
\text { score }^{*}\end{array}$ \\
\hline & & & & R.LIIHADELAQMWK.V & \\
\hline \multirow[t]{3}{*}{2209} & gi|298160982 & ROPN1 & Ropporin-1A & R.VALSNWAELTPELLK.I & 105 \\
\hline & & & & R.MLNYIEQEVIGPDGLIK.V & \\
\hline & & & & R.IMEGPAFNFLDAPAVR.V & \\
\hline \multirow[t]{3}{*}{3515} & gi|346986351 & PDHB & $\begin{array}{c}\text { Pyruvate dehydrogenase E1 component subunit } \\
\text { beta, mitochondrial }\end{array}$ & K.TYYMSGGLQSVPIVFR.G & 245 \\
\hline & & & & K.TTHLITVEGGWPQFGIGAEICAR.I & \\
\hline & & & & R.GAAGALLVYDITR.R & \\
\hline \multirow[t]{2}{*}{5206} & gi|464526 & RAB2 & Ras-related protein Rab-2 & R.DTFNHLTTWLEDAR.Q & 248 \\
\hline & & & & R.FQPVHDLTIGVEFGAR.M & \\
\hline 5404 & gi|89153 & APOA1 & Apolipoprotein A-I & R.DYVAQFEASALGK.H & 34 \\
\hline \multirow[t]{2}{*}{5712} & gi|21263966 & SUCLA2 & $\begin{array}{l}\text { Succinyl-CoA ligase [ADP-forming] subunit } \\
\text { beta, mitochondrial }\end{array}$ & K.LHGGTPANFLDVGGGATVHQVTEAFK.L & 44 \\
\hline & & & & R.LLADPTGAFGK.E & \\
\hline \multirow[t]{2}{*}{6207} & gi|47523086 & PRDX5 & Peroxiredoxin-5, mitochondrial & R.FSMVIEDGIVK.S & 150 \\
\hline & & & & K.VGDAIPSWFEGEPEKK.V & \\
\hline \multirow{2}{*}{7106} & sil75052403 & 6 & Acrocin-hinding nrote & R.FYGLDLYGGLR.M & 125 \\
\hline & $91 / / 5052483$ & $A C R B P$ & Acrosin-Dinaing procem & R.VASWLQTEFLSFQDGDFPTK.I & 125 \\
\hline \multirow{2}{*}{8326} & gil13195731 & GPY4 & Phospholipid hydroperoxide glutathione & K.TEVNYTQLVDLHAR.Y & 109 \\
\hline & 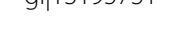 & 年 & peroxidase & R.QEPGSDAEIKEFAAGYNVK.F & 年 \\
\hline \multirow{2}{*}{9117} & مان 66900208 & 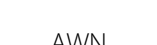 & Snermadhecin AWA & K.EYVELLDGPPGSEIIGK.I & 173 \\
\hline & 9100090200 & AVVIV & spermaanesin Avviv & R.ASPFHIYYYADPEGPLPFPYFER.Q & $1 / 3$ \\
\hline 9212 & gi|113205666 & LOC733605 & NADH dehydrogenase 1 beta subcomplex 6 & R.IFPGDTILETGEVIPLMK.E & 48 \\
\hline
\end{tabular}

${ }^{*}$ MASCOT score is $-10 \log (P)$, where $P$ is the probability that the observed match is a random event. Individual scores $>30$ indicate identity or extensive homology $(P<0.05)$.

and membrane fusion and are localized to the acrosomal membrane during acrosome formation in spermatozoa [36-38]. Capacitated spermatozoa undergo the acrosome reaction, a process of acrosomal exocytosis $[39,40]$. Therefore decreased expression of RAB2 after-capacitation suggests that RAB2 is involved in structural modification of the acrosome to induce acrosomal exocytosis following capacitation. On the other hand, PHGPx contributes to cross-linking in mitochondrial capsules of mammalian spermatozoa and provides structural stability [41,42]. Therefore, similar to RAB2, the decrease PHGPx in spermatozoa after capacitation (Figures 3A, 4I, and J) might promote acrosomal exocytosis. Foresta et al. reported that PHGPx was important for fertility [43]. They also reported that its over-expression increased the resistance of mouse NSC-34 motor neuron-like cells, which is thought to induce mitochondrial abnormalities in patients with amyotrophic lateral sclerosis. In the present study, we identified PHGPx in the head and tail of spermatozoa (Figure 4) and predicted its involvement in regulating glutathione metabolism based on an analysis in Pathway Studio (Table 3). These results indicated that before-capacitation spermatozoa metabolize glutathione, which may facilitate capacitation in spermatozoa by promoting the acrosome reaction, fertilization, and other events.

Another protein that decreased after capacitation was PDHB (Figure 3A). PDHB is one of 7 subunits of the pyruvate dehydrogenase complex $(\mathrm{PDH})$ family, which converts pyruvate to acetyl-CoA during aerobic oxidation of glucose [44-46]. PDHB is a phospho-tyrosine protein involved in capacitation in human spermatozoa [47]. In the present study, we used Pathway Studio to identify PDHB's potential involvement in regulating the tricarboxylic acid cycle, adipocytokine, and insulin action (Table 3). Together with its localization in sperm flagella [48], these finding provide further insight into PDHB's involvement in energy production and metabolism in order to control sperm motility and hyperactivation during capacitation.

The proteins that increased ( $>3$-fold) in after-capacitation included LOC733605, PRDX5, APOA1, SUCLA2, ACRBP, ROPN1, and AWN (Figure 3B). PRDX5 is a thioredoxin peroxidase that protects spermatozoa from oxidative stress $[49,50]$. Recently, O'Flaherty and de Souza reported that PRDX5 was localized to the acrosome, post-acrosome and midpiece of spermatozoa [51]. Its localization to multiple 


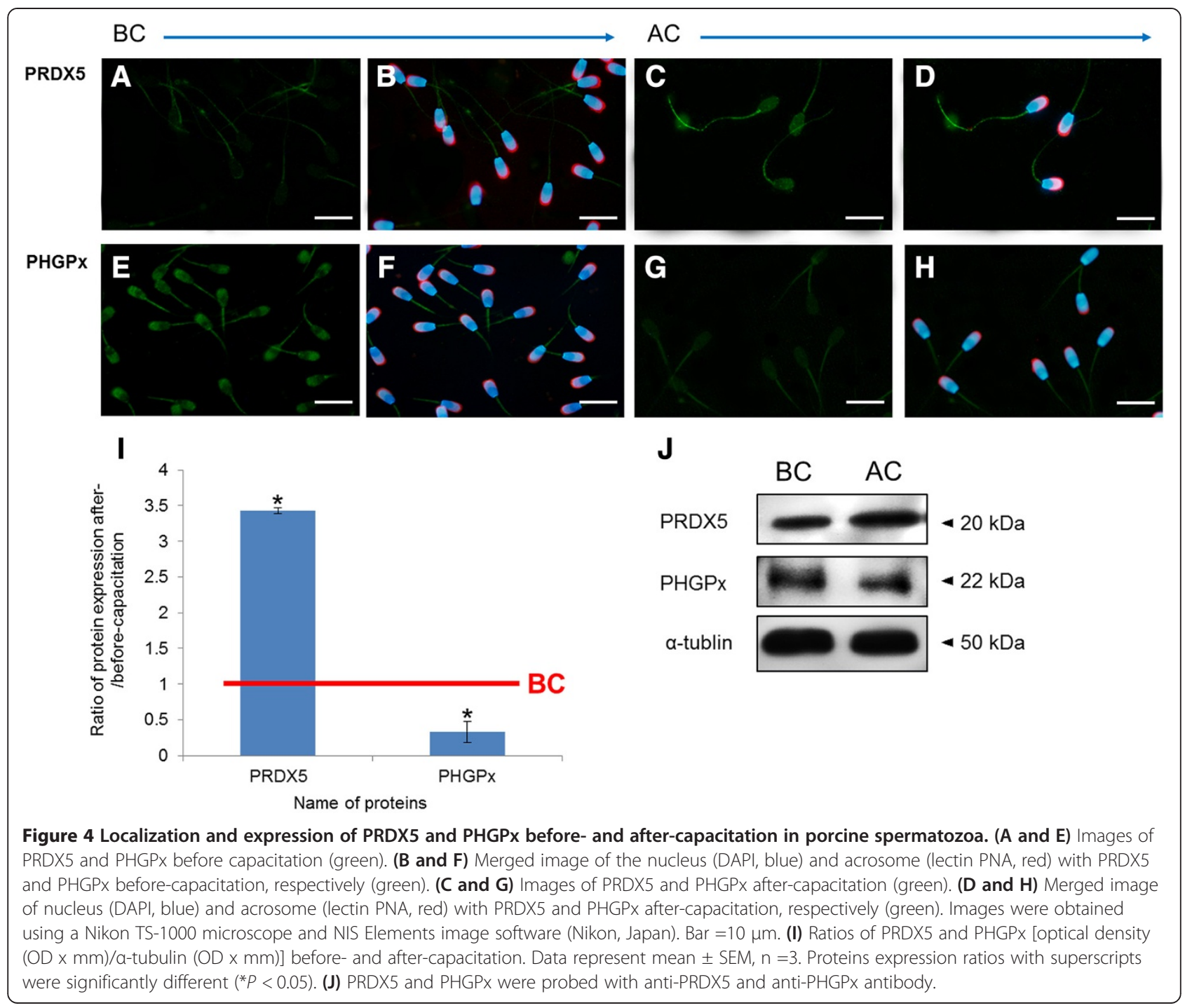

Table 3 Signaling pathways associated with differentially expressed proteins as identified by Pathway Studio

\begin{tabular}{lcc}
\hline \multicolumn{1}{c}{ Signaling pathways } & Overlapping entities & $P$-value \\
\hline Metabolic Pathways & & \\
Tricarboxylic acid cycle & SUCLA2, PDHB & 0.002 \\
Glutathione metabolism & PHGPX, PRDX5 & 0.011 \\
Cell Signaling Pathways & & \\
Adipocytokine signaling & SUCLA2, APOA1, PDHB & 0.008 \\
Insulin action & SUCLA2, APOA1, PDHB & 0.012 \\
\hline
\end{tabular}

Differentially expressed proteins were entered into Pathway Studio to identify the corresponding signaling pathways that potentially regulate capacitation. Among the differentially expressed proteins ( $>3$-fold) of before- and aftercapacitation, at least 5 exhibited regulatory roles in single or more pathways simultaneously $(P<0.05)$ sites indicates its potential involvement in different physiological processes responsible for fertilization in the spermatozoon. In the present study, we identified PRDX5 in head and midpiece of spermatozoa (Figure 4). Its increased expression after capacitation (Figures 3B, 4I and J) and its localization suggest that PRDX5 plays an important role in sperm-oocyte binding as well as regulating energy production by mitochondria in the midpiece. A similar result was also reported in an earlier study in boar spermatozoa [52].

APOA1 has been reported to induce cholesterol efflux in spermatozoa $[53,54]$. Cholesterol efflux from the sperm membrane regulates multiple signaling cascades responsible for motility, hyperactivation, and capacitation [55]. Thérien et al. reported that APOA1 is part of high-density lipoprotein (HDL) and triggers the acrosome reaction [56]. The APOA1 is known as a seminal plasma protein that affects sperm-oocyte binding and 


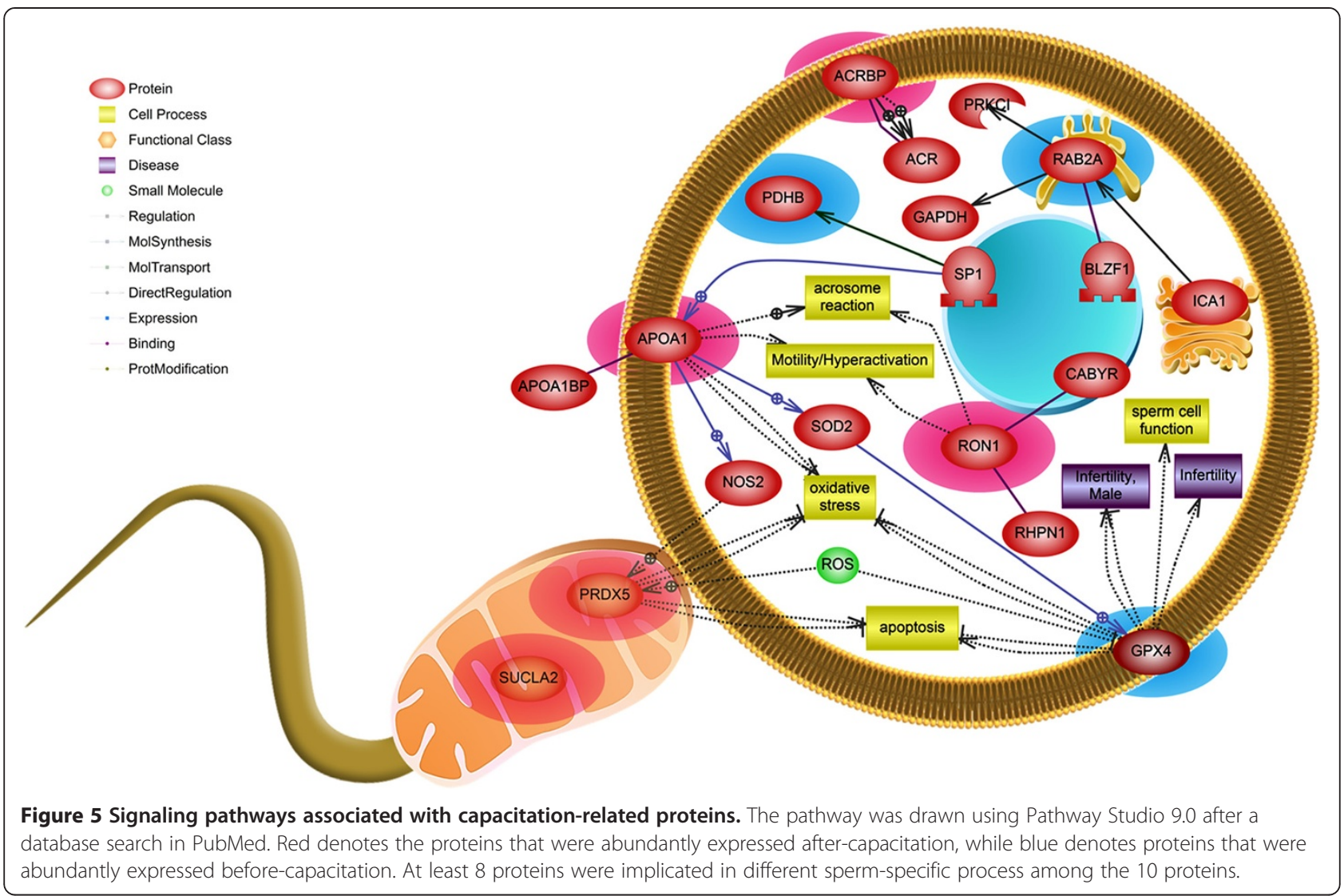

ultimately male fertility. In present study, APOA1 was increased after capacitation. It is plausible to suggest that APOA1 come from fetal bovine serum used in capacitation media. However, we identified this protein in mature spermatozoa where the seminal plasma had removed completely by discontinuous Percoll gradients [16,31,52,57]. Therefore, our study provides evidence that APOA1 might also be present in spermatozoa and play an essential role in fertilization.

In the present study, we identified increased expression of ACRBP in after-capacitation. ACRBP regulates the release of acrosin from the acrosome of spermatozoa [58]. Acrosin is the major proteinase that lyses the zona pellucida and facilitates the penetration of the sperm through the innermost glycoprotein layers of the ovum. Interestingly, recent study suggested that ACRBP can be used as marker to predict boar sperm freezability [59]. Therefore, the capacitation-associated increase in ACRBP plays an important role in the control of male fertility. Another capacitation-induced protein is ROPN1. Fujita et al. reported that ROPN1 is localized to the sperm flagella [60]. Another study reported decreased expression of ROPN1 in the spermatozoa of patients with low sperm motility [61]. Therefore, we hypothesize that ROPN1 contributes to sperm hyperactivation. Indeed, sperm hyperactivation facilitate the release from oviductal storage and propels them into the oviductal lumen and matrix of the cumulus oophorus during fertilization.

NADH dehydrogenase and succinyl-CoA ligase are located in sites I and II of the mitochondrial electron transport chain, respectively. Therefore, these enzymes affect motility and hyperactivation of human spermatozoa [62]. NADH dehydrogenase and succinyl-CoA ligase were identified as substrates of protein kinase A (PKA). In the present study, LOC733605 and SUCLA2 were increased in after-capacitation (Figure 3B). In addition, we demonstrated the potential involvement of SUCLA2 in the tricarboxylic acid cycle, adipocytokine signaling, and insulin action by Pathway Studio (Table 3). Therefore, spermatozoa may participate in various metabolic and cell signaling pathways after capacitation that affects the subsequent acrosome reaction and fertilization.

The spermadhesin proteins are constituents of boar seminal plasma, attach to the sperm acrosome thereby assist sperm-egg interaction [63]. Five spermadhesin proteins were identified in the boar semen, such as PSP-I, PSP-II, AQN-1, AQN-3, and AWN [64]. A review of literature demonstrated that spermadhesin AWN regulates the phospholipid-binding activity in spermatozoa, thus promoting the capacitation and the acrosomal stabilization [65]. Therefore, high levels of AWN after capacitation (Figure $3 \mathrm{~B}$ ) might represent the potentiality of the 
capacitated spermatozoa to bind with eggs zona pellucida during the initial stages of the sperm-egg interaction for fertilization. Since, only capacitated spermatozoa are able to undergo the acrosome reaction, binding to the zona pellucida, and fusion to the oocyte membrane [66]. In contrast, Dostàlovà et al. [65] reported that the spermadhesin content in boar spermatozoa had been lost during capacitation. This conclusion did not entirely support the finding of present study. Therefore, further studies are required to investigate the role of AWN in capacitation, the acrosome reaction, fertilization, and beyond.

\section{Conclusion}

In the present study, we performed comprehensive proteomic profiling of boar spermatozoa under capacitation conditions. We identified proteins involved in capacitation and their signaling pathways. To the best of our knowledge, this is the first study to identify 10 proteins that undergo dramatic changes in expression ( $>3$-fold) during capacitation in boar spermatozoa. Additionally, Pathway Studio was used to identify at least 5 proteins implicated signaling pathways (Table 3 ) and to illustrate the cellular pathways regulated by the identified proteins in spermatozoa (Figure 5). However, a few of the identified proteins have unknown functions. In addition, some proteins exhibited various functions, and although they have diverse roles in the whole organism, their specific functions in spermatozoa are unknown. Therefore, further studies must identify the functions of these proteins in sperm cells. Likewise, these candidate markers might be useful for designing diagnostic tools to evaluate and/ or predict fertility-related diseases and male infertility during capacitation.

\section{Methods}

\section{Sample preparation}

Semen samples were collected from 12 individual Landrace males (Sunjin Co., Danyang, Korea) with normal fertility (pregnancy rate, 90\% \pm 1.44 ; average litter size, $10.75 \pm$ 0.39 ), and samples were divided randomly into 3 groups for experimental replication $(n=4)$. To avoid individual male factors, each group's semen samples were mixed together. Pooled samples were washed at $500 \times g$ for $20 \mathrm{~min}$ with a discontinuous $(70 \%[\mathrm{v} / \mathrm{v}]$ and $35 \%[\mathrm{v} / \mathrm{v}])$ Percoll gradient (Sigma, St Louis, MO, USA) to remove seminal plasma and dead spermatozoa [16]. Then, the washed samples were divided into 2 groups: before-capacitation and after-capacitation spermatozoa. For the after-capacitation samples, further incubation was performed with modified tissue culture media (mTCM) 199 (containing 10\% fetal bovine serum $[\mathrm{v} / \mathrm{v}$ ], $0.91 \mathrm{mM}$ sodium pyruvate, $3.05 \mathrm{mM}$ D-glucose, $2.92 \mathrm{mM}$ calcium lactate, $2.2 \mathrm{~g} / \mathrm{L}$ sodium bicarbonate and $10 \mu \mathrm{g} / \mathrm{mL}$ heparin) (Sigma, St Louis, MO, USA) for $30 \mathrm{~min}$ at $37^{\circ} \mathrm{C}$ under an atmosphere of $5 \% \mathrm{CO}_{2}$ in air $[26,27,66]$. All procedures were performed according to guidelines for the ethical treatment of animals and approved by Institutional Animal Care and Use Committee of Chung-Ang University.

\section{Computer-assisted sperm analysis}

To analyze motility and motion kinematics of beforecapacitation sample, the sample was pre-incubated with mTCM 199 (without 10\% fetal bovine serum [v/v] and $10 \mu \mathrm{g} / \mathrm{mL}$ heparin) for $10 \mathrm{~min}$ at $37^{\circ} \mathrm{C}$ under an atmosphere of $5 \% \mathrm{CO}_{2}$ in air. The same parameters of aftercapacitation sample were analyzed following $30 \mathrm{~min}$ incubation of the sample with capacitation media (mention earlier). A computer-assisted sperm analysis (CASA) system (sperm analysis imaging system version (SAIS)PLUS 10.1; Medical Supply, Seoul, Korea) was used to analyze sperm motility (\%) and motion kinematics. Briefly, $10 \mu \mathrm{L}$ of sample was placed in a Makler chamber (Makler, Haifa, Israel). The filled chamber was placed on a stage preheated to $37^{\circ} \mathrm{C}$. Using a $10 \times$ objective in-phase contrast mode, the image was relayed, digitized, and analyzed by SAIS software. The movement of at least 250 sperm cells was recorded for each sample from more than five randomly selected fields per replicate.

\section{H33258/CTC assessment of capacitation status}

Capacitation status was determined by the dual staining method (H33258/CTC) described previous [9,10,67] Briefly, $135 \mu \mathrm{L}$ of treated spermatozoa were added to $15 \mu \mathrm{L}$ of H33258 solution (10 $\mu \mathrm{g}$ H33258/mL Dulbecco's phosphate buffered saline (DPBS) and incubated for $2 \mathrm{~min}$ at room temperature (RT). Excess dye was removed by layering the mixture over $250 \mu \mathrm{L}$ of $2 \%(\mathrm{w} / \mathrm{v})$ polyvinylpyrrolidone in DPBS. The supernatant was discarded after centrifuging at $100 \times \mathrm{g}$ for $2.5 \mathrm{~min}$. The pellet was resuspended in $100 \mu \mathrm{L}$ of DPBS; $100 \mu \mathrm{l}$ of a chlortetracycline fluorescence (CTC) solution (750 mM CTC in $5 \mu \mathrm{L}$ buffer composed of $20 \mathrm{mM}$ Tris, $130 \mathrm{mM} \mathrm{NaCl}$, and $5 \mathrm{mM}$ cysteine, $\mathrm{pH}$ 7.4). Capacitation status was observed with a Microphot-FXA microscope (Nikon) under epifluorescent illumination using ultraviolet BP 340-380/LP 425 and BP 450-490/LP 515 excitation/emission filters for H33258 and CTC, respectively. The patterns of capacitation status in the spermatozoa were classified as live non-capacitated (F, bright green fluorescence distributed uniformly over entire sperm head, with or without a stronger fluorescent line at the equatorial segment), live capacitated ( $B$, green fluorescence over the acrosomal region and a dark postacrosomal region), or live acrosome reacted (AR, sperm showing a mottled green fluorescence over the head, green fluorescence only in the post acrosomal region, or no fluorescence over the head) $[9,10]$. Two slides per sample were evaluated with at least 400 spermatozoa per slide. 


\section{DE and gel-image analysis}

To extract proteins from the spermatozoa, $50 \times 10^{6}$ spermatozoa were incubated in rehydration buffer containing $7 \mathrm{M}$ urea (Sigma, St Louis, MO, USA), $2 \mathrm{M}$ thiourea (Sigma, St Louis, MO, USA), 4\% (w/v) CHAPS (USB, Cleveland, OH, USA), 0.05\% (v/v) Triton X-100 (Sigma, St Louis, MO, USA), 1\% (w/v) octyl $\beta$-D-glucopyranoside, $24 \mu \mathrm{M}$ PMSF (Sigma, St Louis, MO, USA), 1\% (w/v) DTT (Sigma, St Louis, MO, USA), 0.5\% (v/v) IPG Buffer, and $0.002 \%(\mathrm{w} / \mathrm{v})$ bromophenol blue at $4{ }^{\circ} \mathrm{C}$ for $1 \mathrm{~h}$. Then, $250 \mu \mathrm{g}$ of solubilized protein from the sperm cells in $450 \mu \mathrm{L}$ of rehydration buffer was placed in a rehydration tray with $24 \mathrm{~cm}$-long NL Immobiline DryStrips (pH 3-11; Amersham, Piscataway, NJ, USA) for $12 \mathrm{~h}$ at $4^{\circ} \mathrm{C}$. First dimension electrophoresis was performed using an IPGphor IEF device and then the strips were focused at $100 \mathrm{~V}$ for $1 \mathrm{~h}, 200 \mathrm{~V}$ for $1 \mathrm{~h}, 500 \mathrm{~V}$ for $1 \mathrm{~h}, 1,000 \mathrm{~V}$ for $1 \mathrm{~h}$,

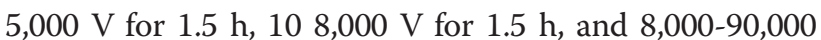
Vhr. After iso-electrofocusing, the strips were equilibrated a second After iso-electrofocusing, the strips were equilibrated with equilibration buffer A containing $6 \mathrm{M}$ urea, $75 \mathrm{mM}$ Tris- $\mathrm{HCl}(\mathrm{pH} 8.8), 30 \%(\mathrm{v} / \mathrm{v})$ glycerol, $2 \%(\mathrm{w} / \mathrm{v})$ SDS, $0.002 \%(\mathrm{w} / \mathrm{v})$ bromophenol blue, and $2 \%(\mathrm{w} / \mathrm{v})$ DTT for $15 \mathrm{~min}$ at RT. The strips were equilibrated for a second time with equilibration buffer B (equilibration buffer A with $2.5 \%[\mathrm{w} / \mathrm{v}]$ iodoacetamide [Sigma] but without DTT for 15 min at RT. Next, 2-DE was carried out with $12.5 \%$ $(\mathrm{w} / \mathrm{v})$ SDS-PAGE gels with the strips at $100 \mathrm{~V}$ for $1 \mathrm{~h}$ and $500 \mathrm{~V}$ until the bromophenol blue front began to migrate off the gels. The gels were silver-stained for image analysis according to the manufacturer's instructions (Amersham, Piscataway, NJ, USA). The gels were then scanned using a high-resolution GS-800 calibrated scanner (Bio-Rad, Hercules, CA, USA). Detected spots were matched and analyzed by comparing the gels from spermatozoa before- and after-capacitation using PDQuest 8.0 software (Bio-Rad, Hercules, CA, USA). The gel from beforecapacitation spermatozoa was used as a control. Finally, the density of the spots was calculated and normalized as the ratio of the spot on the after-capacitation gel to that on the before-capacitation gel.

\section{In-gel digestion}

The proteins were subjected to in-gel trypsin digestion. Excised gel spots were destained with $100 \mu \mathrm{l}$ of destaining solution $(30 \mathrm{mM}$ potassium ferricyanide and $100 \mathrm{mM}$ sodium thiosulfate) with shaking for $5 \mathrm{~min}$. After removing the solution, the gel spots were incubated with $200 \mathrm{mM}$ ammonium bicarbonate for $20 \mathrm{~min}$. The gel pieces were dehydrated with $100 \mu \mathrm{L}$ of acetonitrile and dried in a vacuum centrifuge. The above procedure was repeated 3 times. The dried gel pieces were rehydrated with $20 \mu \mathrm{L}$ of $50 \mathrm{mM}$ ammonium bicarbonate containing $0.2 \mu \mathrm{g}$ modified trypsin (Promega, Madison, WI, USA) for $45 \mathrm{~min}$ on ice. After removing the solution, $30 \mu \mathrm{L}$ of $50 \mathrm{mM}$ ammonium bicarbonate was added. The digestion was performed overnight at $37^{\circ} \mathrm{C}$. The peptide solution was desalted using a C18 nano column (homemade, Waters Corp, Milford, MA, USA).

\section{Desalting and concentration}

Custom-made chromatographic columns were used for desalting and concentrating the peptide mixture prior to MS analysis. A column consisting of $100-300 \mathrm{~nL}$ of Poros reverse phase R2 material $(20-30 \mu \mathrm{m}$ bead size, Perseptive Biosystems, Framingham, MA, USA) was packed in a constricted GELoader tip (Eppendorf, Hamburg, Germany). A $10 \mathrm{~mL}$ syringe was used to force liquid through the column by applying gentle air pressure. Thirty microliters of the peptide mixture from the digestion supernatant was diluted in $30 \mu \mathrm{L}$ of $5 \%$ formic acid, loaded onto the column, and washed with $30 \mu \mathrm{L}$ of $5 \%$ formic acid. For MS/MS analyses, the peptides were eluted with $1.5 \mu \mathrm{L}$ of $50 \%$ methanol $/ 49 \%$ $\mathrm{H}_{2} \mathrm{O} / 1 \%$ formic acid directly into a pre-coated borosilicate nano-electrospray needle (New Objective, Woburn, MA, USA).

\section{ESI-MS/MS}

Proteins generated by in-gel digestion were subjected to MS/MS using a nano-ESI on a Q-TOF2 mass spectrometer (AB Sciex Instruments, Framingham, MA, USA). The source temperature was RT. A potential of $1 \mathrm{kV}$ was applied to the pre-coated borosilicate nano-electrospray needles (New Objective, Woburn, MA, USA) in the ion source, combined with a nitrogen back-pressure of 0 $5 \mathrm{psi}$ to produce a stable flow rate $(10-30 \mathrm{~nL} / \mathrm{min})$. The cone voltage was $40 \mathrm{~V}$. A quadrupole analyzer was used to select precursor ions for fragmentation in the hexapole collision cell. The collision gas was argon at a pressure of $6-7 \times 10^{-5}$ mbar and the collision energy was $25-40 \mathrm{~V}$. Product ions were analyzed using an orthogonal TOF analyzer that was fitted with a reflector, which was a micro-channel plate detector, and a time-to-digital converter. The data were processed using a peptide sequencing system.

\section{Database search}

A MS/MS ion search was assigned as the ion search option in MASCOT software (Matrix Science, Boston, MA, USA). Peptide fragment files were obtained from the peptide peaks in ESI-MS by ESI-MS/MS. Trypsin was selected as the enzyme with one potentially missed cleavage site. ESI-QTOF was selected as the instrument type. The peptide fragment files were searched within the database using the Mascot search engine (Matrix Science, Boston, MA, USA), and results were limited to Sus scrofa taxonomy. Oxidized methionine was set as a 
variable modification, and carbamidomethylated cysteine was set as a fixed modification. The mass tolerance was set at \pm 1 and $\pm 0.6 \mathrm{Da}$ for the peptides and fragments, respectively. High-scoring was defined as those above the default significance threshold in MASCOT $(P<0.05$, peptide score $>30$ ).

\section{Western blotting}

To evaluate the capacitation status, tyrosine phosphorylated proteins were detected with an anti-Phosphotyrosine (4G10) antibody. In order to confirm the 2-DE results, Western blotting was performed with anti-phospholipid hydroperoxide glutathione peroxidase (PHGPx) and antiperoxiredoxin-5, mitochondrial (PRDX5) antibodies to quantify 3 individual boar spermatozoa before- and aftercapacitation. Western blotting was performed as described previously with modification $[9,10,68]$. The samples were washed twice with DPBS and centrifuged at $10,000 \times g$ for $5 \mathrm{~min}$. Afterwards, the pellets were re-suspended and incubated with sample buffer containing 5\% 2-mercaptoethanol for $10 \mathrm{~min}$ at RT. After incubation, the insoluble fractions were separated by centrifugation at $10,000 \times g$ for $10 \mathrm{~min}$. The samples were subjected to SDS-PAGEs using a $12 \%$ mini-gel system (Amersham, Piscataway, NJ, USA), and the separated proteins were transferred to PVDF membranes (Amersham, Piscataway, NJ, USA). The membranes were blocked with 3\% blocking agent (Amersham, Piscataway, NJ, USA) for $1 \mathrm{~h}$ at RT. Tyrosine phosphorylated proteins, PHGPx and PRDX5 proteins from beforeand after-capacitation spermatozoa were immunodetected with an anti-Phosphotyrosine (4G10) mouse polyclonal antibody (Millipore, Darmstadt, Germany), anti-PHGPx rabbit polyclonal antibody (Abcam, Cambridge, UK), and anti-PRDX5 rabbit polyclonal antibody (Abcam, Cambridge, UK), respectively, that were diluted in $3 \%$ blocking agent $(1 \mu \mathrm{g} / \mathrm{ml})$ for $2 \mathrm{~h}$ at RT. Then, the membranes were incubated with an HRP conjugated goat antimouse IgG or anti-rabbit IgG (Abcam, Cambridge, UK) diluted in $3 \%$ blocking agent $(1: 5,000)$ for $1 \mathrm{~h}$ at RT. The membranes were washed 3 times with DPBS containing $0.1 \%$ Tween-20 (PBS-T). The proteins on the membranes were detected with an enhanced chemiluminescence (ECL) technique using ECL reagents. Proteins on membranes were stripped with membrane stripping solution (2\% SDS, $100 \mathrm{mM}$ mercaptoethanol and $62 \mathrm{mM}$ Tris-cl) after detection. Then, $\alpha$-tubulin was detected by incubation with a monoclonal anti- $\alpha$-tubulin mouse antibody (Abcam, Cambridge, UK) diluted in 3\% blocking agent $(1: 10,000)$ for $2 \mathrm{~h}$ at RT. Membranes were incubated with an HRP-conjugated goat anti-mouse IgG (Abcam, Cambridge, UK) diluted in 3\% blocking agent $(1: 10,000)$ for $1 \mathrm{~h}$ at RT. The $\alpha$-tubulin on the membranes was detected with an ECL technique using ECL reagents. All bands were scanned with a GS-800 calibrated imaging densitometer (Bio-Rad, Hercules, CA, USA) and analyzed with Quantity One software (Bio-Rad, Hercules, CA, USA). Finally, the signal intensity ratios of the bands were calculated for tyrosine phosphorylated proteins, PHGPx, and PRDX5 as compared with $\alpha$-tubulin.

\section{Immunofluorescence assay}

To confirm the cellular localization of PHGPx and PRDX5, immunocytochemistry was performed in before- and aftercapacitation spermatozoa. Before- and after-capacitation sperm suspensions were placed on slides and then dried. The slides were fixed with $3.7 \%$ paraformaldehyde for $30 \mathrm{~min}$ at $4^{\circ} \mathrm{C}$, washed with PBS-T, and blocked with blocking solution (5\% BSA in PBS-T) for $1 \mathrm{~h}$ at $37^{\circ} \mathrm{C}$. Sample were incubated with anti-PHGPx and anti-PRDX5 rabbit polyclonal antibodies (Amersham, Piscataway, NJ, USA) diluted in blocking solution (1:200) and lectin Peanut agglutinin (PNA) conjugated with Alexa Fluor 647 (Molecular Probes, Carlsbad, CA, USA) diluted in blocking solution $(1: 100)$ overnight at $4{ }^{\circ} \mathrm{C}$. Then, the slides were incubated for $2 \mathrm{~h}$ at RT with fluorescein isothiocyanate conjugated goat anti-rabbit IgG (Abcam, Cambridge, UK) diluted in blocking solution (1:200) for $2 \mathrm{~h}$ at RT. Spermatozoa were counterstained with DAPI. The immunofluorescence signals were visualized under $\times 600$ magnifications with a Nikon TS-1000 microscope using NIS Elements image software (Nikon, Tyoko, Japan).

\section{Signaling pathway}

Pathway Studio (v 9.0, Aridane Genomics, Rockville, MD, USA) was used to predict the biological functions and signaling pathways of the differentially expressed proteins. A list of identified proteins was entered into Pathway Studio in order to determine matching pathways for each protein. Metabolic pathways and cell signaling pathways were confirmed by the PubMed Medline hyperlink that was embedded in each node.

\section{Statistical analysis}

The data were analyzed with SPSS (v. 18.0, Chicago, IL, USA). The student's two-tailed $t$-test was used to compare the capacitation conditions after normality and variance homogeneity test. $P$ values $<0.05$ were considered statistically significant. All data are expressed as mean \pm SEM. The probabilities of the signaling pathways were determined using the Fisher exact test $(P<0.05)$.

\section{Competing interests}

The authors declare that they have no competing interests.

\section{Authors' contributions}

WSK, MSR, JSL, JK, SJY, YJP, YAY, and SH performed experiment, analyzed data, and drafted this manuscript. MGP supervised critical design of study, analysis of data, and revised the manuscript. All authors contributed to revise critically for important intellectual content and final approval of the version to be published. 


\section{Acknowledgments}

This work was supported by the National Research Foundation of Korea (NRF) grant funded by the Korea government (MEST) (No. NRF-2014R1A2A2A01002706). June-Sub Lee was supported through the "Chung-Ang University Research Scholarship Grant in 2013-2014," Chung-Ang University, Korea.

\section{Author details}

${ }^{1}$ Department of Animal Science \& Technology, Chung-Ang University, Anseong, Gyeonggi-do 456-756, Republic of Korea. ${ }^{2}$ Animal Biotechnology Division, National Institute of Animal Science, RDA, Suwon, Gyeonggi-do 441-706, Republic of Korea.

Received: 9 May 2014 Accepted: 6 October 2014

Published: 14 October 2014

\section{References}

1. Zaneveld $L$, De Jonge CJ, Anderson RA, Mack SR: Human sperm capacitation and the acrosome reaction. Hum Reprod 1991, 6:1265-1274.

2. Fraser $L R, M c D e r m o t t ~ A: C^{2+}$-related changes in the mouse sperm capacitation state: a possible role for $\mathrm{Ca}^{2+}$-ATPase. J Reprod Fertil 1992, 96:363-377.

3. Luconi M, Krausz C, Forti G, Baldi E: Extracellular calcium negatively modulates tyrosine phosphorylation and tyrosine kinase activity during capacitation of human spermatozoa. Biol Reprod 1996, 55:207-216.

4. Kirichok Y, Navarro B, Clapham DE: Whole-cell patch-clamp measurements of spermatozoa reveal an alkaline-activated $\mathrm{Ca}^{2+}$ channel. Nature 2006, 439:737-740.

5. Wang D, Hu J, Bobulescu IA, Quill TA, McLeroy P, Moe OW, Garbers DL: A sperm specific $\mathrm{Na}^{+} / \mathrm{H}^{+}$exchanger ( $\mathrm{SNHE}$ ) is critical for expression and in vivo bicarbonate regulation of the soluble adenylyl cyclase (SAC). Proc Natl Acad Sci U S A 2007, 104:9325-9330.

6. Arcelay E, Salicioni AM, Wertheimer E, Visconti PE: Identification of proteins undergoing tyrosine phosphorylation during mouse sperm capacitation. Int J Dev Biol 2008, 52:463-472.

7. Kaneto M, Krisfalusi M, Eddy EM, O'Brien DA, Miki K: Bicarbonate induced phosphorylation of p270 protein in mouse sperm by cAMP-dependent protein kinase. Mol Reprod Dev 2008, 75:1045-1053.

8. Visconti PE: Understanding the molecular basis of sperm capacitation through kinase design. Proc Natl Acad Sci U S A 2009, 106:667-668.

9. Kwon WS, Park YJ, Kim YH, You YA, Kim IC, Pang MG: Vasopressin effectively suppresses male fertility. PLoS One 2013, 8:e5419.

10. Kwon WS, Park YJ, el SA M, Pang MG: Voltage-dependent anion channels are a key factor of male fertility. Fertil Steril 2013, 99:354-361.

11. Chang MC: Fertilizing capacity of spermatozoa deposited into the fallopian tubes. Nature 1951, 168:697-698.

12. Austin CR: Observations on the penetration of the sperm in the mammalian egg. Aust J Sci Res B 1951, 4:581-596.

13. Secciani F, Bianchi L, Ermini L, Cianti R, Armini A, La Sala GB, Focarelli R, Bini L, Rosati F: Protein profile of capacitated versus ejaculated human sperm. J Proteome Res 2009, 8:3377-3389.

14. Baker MA, Reeves G, Hetherington L, Aitken RJ: Analysis of proteomic changes associated with sperm capacitation through the combined use of IPG-strip pre-fractionation followed by RP chromatography LC-MS/MS analysis. Proteomics 2010, 10:482-495.

15. Kota V, Dhople VM, Shivaji S: Tyrosine phosphoproteome of hamster spermatozoa: role of glycerol-3-phosphate dehydrogenase 2 in sperm capacitation. Proteomics 2009, 9:1809-1826.

16. Flesch FM, Colenbrander B, van Golde LM, Gadella BM: Capacitation induces tyrosine phosphorylation of proteins in the boar sperm plasma membrane. Biochem Biophys Res Commun 1999, 7:787-792.

17. Jagan Mohanarao G, Atreja SK: Identification of capacitation associated tyrosine phosphoproteins in buffalo (Bubalus bubalis) and cattle spermatozoa. Anim Reprod Sci 2011, 123:40-47.

18. Miller D, Ostermeier GC: Towards a better understanding of RNA carriage by ejaculate spermatozoa. Hum Reprod Update 2006, 12:757-767.

19. Gur Y, Breitbart H: Protein synthesis in sperm: dialog between mitochondria and cytoplasm. Mol Cell Endocrinol 2008, 282:45-55.

20. Wang S, Wang W, Xu Y, Tang M, Fang J, Sun H, Sun Y, Gu M, Liu Z, Zhang Z, Lin F, Wu T, Song N, Wang Z, Zhang W, Yin C: Proteomic characteristics of human sperm cryopreservation. Proteomics 2014, 14:298-310

21. Yuan J: Protein degradation and phosphorylation after freeze thawing result in spermatozoon dysfunction. Proteomics 2014, 14:155-156.
22. Bonde JP, Ernst E, Jensen TK, Hjollund NH, Kolstad H, Henriksen TB, Scheike T, Giwercman A, Olsen J, Skakkebaek NE: Relation between semen quality and fertility: a population-based study of 430 first-pregnancy planners. Lancet 1998, 352:1172-1177.

23. Morrell JM, Johannisson A, Dalin AM, Hammar L, Sandebert T, Rodriguez Martinezet H: Sperm morphology and chromatin integrity in Swedish warmblood stallions and their relationship to pregnancy rates. Acta Vet Scand 2008, 50:1-7.

24. Kastelic JP, Thundathil JC: Breeding soundness evaluation and semen analysis for predicting bull fertility. Reprod Domest Anim 2008, 43:368-373.

25. Budworth PR, Amann RP, Chapman PL: Relationships between computerized measurements of motion of frozen-thawed bull spermatozoa and fertility. J Androl 1988, 9:41-54.

26. Jasko DJ, Lein DH, Foote RH: Determination of the relationship between sperm morphologic classifications and fertility in stallions: 66 cases (1987-1988). J Am Vet Med Assoc 1990, 197:389-394.

27. Sánchez-Partida LG, Windsor DP, Eppleston J, Setchell BP, Maxwell WM: Fertility and its relationship to motility characteristics of spermatozoa in ewes after cervical, transcervical, and intrauterine insemination with frozen-thawed ram semen. J Androl 1999, 20:280-288.

28. Oh SA, Park YJ, You YA, Mohamed EA, Pang MG: Capacitation status of stored boar spermatozoa is related to litter size of sows. Anim Reprod SCi 2010, 121:131-138.

29. Oh SA, You YA, Park YJ, Pang MG: The sperm penetration assay predicts the litter size in pigs. Int J Androl 2010, 33:604-612.

30. Lewis SE: Is sperm evaluation useful in predicting human fertility? Reproduction 2007, 34:31-40

31. Park YJ, Kwon WS, Oh SA, Pang MG: Fertility-related proteomic profiling bull spermatozoa separated by percoll. J Proteome Res 2012, $11: 4162-4168$

32. Peddinti D, Nanduri B, Kaya A, Feugang JM, Burgess SC, Memili E: Comprehensive proteomic analysis of bovine spermatozoa of varying fertility rates and identification of biomarkers associated with fertility. BMC Syst Biol 2008, 2:19.

33. Oliva R, de Mateo S, Estanyol JM: Sperm cell proteomics. Proteomics 2009 9:1004-1017.

34. Aitken RJ, Baker MA: The role of proteomics in understanding sperm cell biology. Int J Androl 2008, 31:295-302

35. Gur Y, Breitbart H: Mammalian sperm translate nuclear-encoded proteins by mitochondrial-type ribosomes. Genes Dev 2006, 15:411-416.

36. Mountjoy JR, Xu W, McLeod D, Hyndman D, Oko R: RAB2A: a major subacrosomal protein of bovine spermatozoa implicated in acrosomal biogenesis. Biol Reprod 2008, 79:223-232.

37. Pereira-Leal JB, Seabra MC: Evolution of the Rab family of small GTP-binding proteins. J Mol Biol 2001, 313:889-901.

38. Stenmark H, Olkkonen VM: The Rab GTPase family. Genome Biol 2001 2:3007.1-3007.7

39. Wu L, Sampson NS: Fucose, mannose, and $\beta$-N-acetylglucosamine glycopolymers initiate the mouse sperm acrosome reaction through convergent signaling pathways. ACS Chem Biol 2014, 9:468-475.

40. Rahman MS, Lee JS, Kwon WS, Pang MG: Sperm proteomics: road to male fertility and contraception. Int J Endocrinol 2013, 2013:360986.

41. Ursini F, Heim S, Kiess M, Maiorino M, Roveri A, Wissing J, Flohé L: Dual function of the selenoprotein PHGPx during sperm maturation. Science 1999, 285:1393-1396.

42. Maiorino M, Roveri A, Benazzi L, Bosello V, Mauri P, Toppo S, Tosatto SC, Ursini F: Functional interaction of phospholipid hydroperoxide glutathione peroxidase with sperm mitochondrion-associated cysteinerich protein discloses the adjacent cysteine motif as a new substrate of the selenoperoxidase. J Bio/ Chem 2005, 280:38395-38402.

43. Foresta C, Flohé L, Garolla A, Roveri A, Ursini F, Maiorino M: Male fertility is linked to the selenoprotein phospholipid hydroperoxide glutathione peroxidase. Biol Reprod 2002, 67:967-971.

44. Young JC, Gould JA, Kola I, lannello RC: Review: pdha-2, past and present. J Exp Zool 1998, 282:231-238

45. Jilka JM, Rahmatulla M, Roche TE: Properties of a newly characterized protein of the bovine kidney pyruvate dehydrogenase complex. J Biol Chem 1986, 261:1858-1867.

46. Yeaman SJ, Hutcheson ET, Roche TE, Pettit FH, Brown JR, Reed LJ: Sites of phosphorylation on pyruvate dehydrogenase from bovine kidney and heart. Biochemistry 1978, 17:2364-2370. 
47. Ficarro S, Chertihin O, Westbrook VA, White F, Jayes F, Kalab P, Marto JA, Shabanowitz J, Herr JC, Hunt DF, Visconti PE: Phosphoproteome analysis of capacitated human sperm. Evidence of tyrosine phosphorylation of a kinase-anchoring protein 3 and valosin-containing protein/p97 during capacitation. J Biol Chem 2003, 278:11579-11589.

48. Fujinoki M, Kawamura T, Toda T, Ohtake H, Ishimoda-Takagi T, Shimizu N, Yamaoka S, Okuno M: Identification of $36 \mathrm{kDa}$ phosphoprotein in fibrous sheath of hamster spermatozoa. Comp Biochem Physiol B Biochem Mol Biol 2004, 137:509-520

49. Wang X, Phelan SA, Forsman-Semb K, Taylor EF, Petros C, Brown A, Lerner CP, Paigen B: Mice with targeted mutation of peroxiredoxin 6 develop normally but are susceptible to oxidative stress. J Biol Chem 2003, 278:25179-25190.

50. Rhee SG, Chae HZ, Kim K: Peroxiredoxins: a historical overview and speculative preview of novel mechanisms and emerging concepts in cell signaling. Free Radic Biol Med 2005, 38:1543-1552.

51. O'Flaherty C, de Souza AR: Hydrogen peroxide modifies human sperm peroxiredoxins in a dose-dependent manner. Biol Reprod 2011, 84:238-247.

52. van Gestel RA, Brewis IA, Ashton PR, Brouwers JF, Gadella BM: Multiple proteins present in purified porcine sperm apical plasma membranes interact with the zona pellucida of the oocyte. Mol Hum Reprod 2007, 13:445-454.

53. Ehrenwald E, Foote RH, Parks JE: Bovine oviductal fluid components and their potential role in sperm cholesterol efflux. Mol Reprod Dev 1990, 25:195-204.

54. Leijonhufvud P, Akerlof E, Pousette A: Structure of sperm activating protein. Mol Hum Reprod 1997, 3:249-253.

55. Travis AJ, Kopf GS: The role of cholesterol efflux in regulating the fertilization potential of mammalian spermatozoa. J Clin Invest 2002, 110:731-736.

56. Thérien I, Soubeyrand S, Manjunath P: Major proteins of bovine seminal plasma modulate sperm capacitation by high-density lipoprotein Biol Reprod 1997, 57:1080-1088.

57. Park YJ, Kim J, You YA, Pang MG: Proteomic revolution to improve tools for evaluating male fertility in animals. J Proteome Res 2013, 12:4738-4747.

58. Fraser LR, Quinn PJ: A glycolytic product is obligatory for initiation of the sperm acrosome reaction and whiplash motility required for fertilization in the mouse. J Reprod Fertil 1981, 61:25-35.

59. Vilagran I, Castillo J, Bonet S, Sancho S, Yeste M, Estanyol JM, Oliva R Acrosin-binding protein (ACRBP) and triosephosphate isomerase (TPI) are good markers to predict boar sperm freezing capacity. Theriogenology 2013, 80:443-450.

60. Fujita A, Nakamura K, Kato T, Watanabe N, Ishizaki T, Kimura K, Mizoguchi A, Narumiya S: Ropporin, a sperm-specific binding protein of rhophilin, that is localized in the fibrous sheath of sperm flagella. J Cell Sci 2000, 113:103-112.

61. Chen J, Wang Y, Wei B, Lai Y, Yan Q, Gui Y, Cai Z: Functional expression of ropporin in human testis and ejaculated spermatozoa. J Androl 2011, 32:26-32.

62. Ruiz-Pesini E, Diez C, Lapeña AC, Pérez-Martos A, Montoya J, Alvarez E, López-Pérez MJ: Correlation of sperm motility with mitochondrial enzymatic activities. Clin Chem 1998, 44:1616-1620.

63. Rodríguez-Martinez H, Iborra A, Martínez P, Calvete JJ: Immunoelectronmicroscopic imaging of spermadhesin AWN epitopes on boar spermatozoa bound in vivo to the zona pellucida. Reprod Fertil Dev 1998, 10:491-497.

64. González-Cadavid V, Martins JA, Moreno FB, Andrade TS, Santos AC, MonteiroMoreira AC, Moreira RA, Moura AA: Seminal plasma proteins of adult boars and correlations with sperm parameters. Theriogenology 2014, 82:697-707.

65. Dostàlovà Z, Calvete JJ, Sanz L, Töpfer-Petersen E: Quantitation of boar spermadhesins in accessory sex gland fluids and on the surface of epididymal, ejaculated and capacitated spermatozoa. Biochim Biophys Acta 1994, 1200:48-54.

66. Eisenbach M: Sperm chemotaxis. Rev Reprod 1999, 4:56-66.

67. el Mohamed SA, Park YJ, Song WH, Shin DH, You YA, Ryu BY, Pang MG: Xenoestrogenic compounds promote capacitation and an acrosome reaction in porcine sperm. Theriogenology 2011, 75:1161-1169.

68. Rahman MS, Kwon WS, Lee JS, Kim J, Yoon SJ, Park YJ, You YA, Hwang S, Pang MG: Sodium nitroprusside suppresses male fertility in vitro. Andrology 2014, doi:10.1111/j.2047-2927.2014.00273.x.

doi:10.1186/1471-2164-15-897

Cite this article as: Kwon et al:: A comprehensive proteomic approach to identifying capacitation related proteins in boar spermatozoa. BMC Genomics 2014 15:897.

\section{Submit your next manuscript to BioMed Central and take full advantage of:}

- Convenient online submission

- Thorough peer review

- No space constraints or color figure charges

- Immediate publication on acceptance

- Inclusion in PubMed, CAS, Scopus and Google Scholar

- Research which is freely available for redistribution 